\title{
Haematological effect of pulsed ultrasound in acute muscular inflammation in rats
}

\author{
Luis Ulisses Signori ${ }^{\text {a,e,* }}$, Silvio Teixeira da Costa ${ }^{a}$, Adão Felix Saurin Neto ${ }^{a}$, \\ Rodrigo Machado Pizzolotto ${ }^{a}$, Cristiane Beck ${ }^{a}$, Graciele Sbruzzi ${ }^{b}$, \\ Antônio Marcos Vargas da Silva ${ }^{d}$, Rodrigo Della Méa Plentz ${ }^{\text {b,c }}$ \\ ${ }^{a}$ Department of Physiotherapy, University of Cruz Alta, RS, Brazil \\ ${ }^{\mathrm{b}}$ Institute of Cardiology of Rio Grande do Sul, University Foundation of Cardiology, RS, Brazil \\ ${ }^{\mathrm{c}}$ Department of Physiotherapy, Federal University of Health Sciences of Porto Alegre, RS, Brazil \\ ${ }^{\mathrm{d}}$ Department of Physiotherapy and Rehabilitation, Federal University of Santa Maria, RS, Brazil \\ ${ }^{\mathrm{e}}$ Institute of Biological Sciences, Federal University of Rio Grande, RS, Brazil
}

\begin{abstract}
Objective To evaluate the effect of low-intensity pulsed ultrasound (LIPUS) on the haematological dynamics of an acute inflammatory process after an iatrogenic muscular lesion.

Design Controlled laboratory study.

Setting Research laboratory.

Participants Eighteen male Wistar rats (weight 350 to $450 \mathrm{~g}$ ) were submitted to surgical incision in the biceps femoris muscle (approximately $50 \%)$, and subsequently subdivided into control $(n=9)$ and LIPUS $(n=9)$ groups.

Intervention Ultrasound $(1.0 \mathrm{MHz})$ was applied at the lesion site in the pulsed mode $(2 \mathrm{~ms}$ on, $8 \mathrm{~ms}$ off $)$ at $0.4 \mathrm{~W} / \mathrm{cm}^{2}$ for $3 \mathrm{minutes}$ at 1,8 and 24 hours post-surgery.

Main outcome measures In these periods, blood was collected through venepuncture of the retro-orbital plexus and evaluated for different types of leukocytes and erythrocytes.

Results LIPUS reduced the total leukocyte count at 1,8 and 24 hours post-surgery ( 1 hour, control $9017.2 \pm 481 \times 10^{3} / \mathrm{mm}^{3}$ vs LIPUS $6189.8 \pm 450 \times 10^{3} / \mathrm{mm}^{3} ; 8$ hours, control $8078.2 \pm 501 \times 10^{3} / \mathrm{mm}^{3}$ vs LIPUS $5371.3 \pm 378 \times 10^{3} / \mathrm{mm}^{3} ; 24 \mathrm{hours}$, control $8192.3 \pm 646 \times 10^{3} / \mathrm{mm}^{3}$ vs LIPUS $\left.6059.1 \pm 503 \times 10^{3} / \mathrm{mm}^{3} ; P<0.001\right)$. The monocyte count was reduced at 8 and 24 hours post-surgery ( 8 hours, control $815.5 \pm 126 \times 10^{3} / \mathrm{mm}^{3}$ vs LIPUS $375.4 \pm 70 \times 10^{3} / \mathrm{mm}^{3}$; 24 hours, control $875.3 \pm 124 \times 10^{3} / \mathrm{mm}^{3}$ vs LIPUS $564.7 \pm 56 \times 10^{3} / \mathrm{mm}^{3} ; P<0.001$ ). The number of segmented neutrophils was only reduced at 1 hour post-surgery (control $5033.1 \pm 397 \times 10^{3} / \mathrm{mm}^{3}$ vs LIPUS $\left.3594.8 \pm 191 \times 10^{3} / \mathrm{mm}^{3} ; P=0.006\right)$, and the lymphocyte count was only reduced at 8 hours post-surgery (control $4759.7 \pm 459 \times 10^{3} / \mathrm{mm}^{3}$ vs LIPUS $2584.1 \pm 356 \times 10^{3} / \mathrm{mm}^{3} ; P=0.003$ ). Changes were not observed in the concentrations of young neutrophils, polibocytes and erythrocytes.
\end{abstract}

Conclusion LIPUS reduced aspects of the inflammatory process following an acute incisional muscular lesion.

Published by Elsevier Ltd on behalf of Chartered Society of Physiotherapy

Keywords: Inflammation; Myoregeneration; Rehabilitation; Ultrasonic therapy; Wounds and injuries

\footnotetext{
* Corresponding author at: Federal University of Rio Grande, Institute of Biological Sciences, Av.: Itália, km 8, Rio Grande, RS, CEP 96201-900, Brazil. Tel.: +55 0533233 6976; fax: +55053 32336976 .

E-mail address: 1.signori@hotmail.com (L.U. Signori).
}

\section{Introduction}

Skeletal muscle injuries are common in clinical sports medicine. Although there is little scientific evidence, therapeutic ultrasound is widely recommended and is used in the treatment of muscle injuries [1]. Conversely, a number of animal studies have suggested the beneficial effects of 
low-intensity pulsed ultrasound (LIPUS) in wound repair of tissues other than muscle [2,3], skin [4], bone [5], tendon [6] and ligament [7]. LIPUS is widely used to accelerate tissue regeneration following injury, but the biological mechanisms for this effect are poorly understood [4].

Injury results in the rapid necrosis of myofibres and the activation of inflammation, which contributes to the removal of necrotic material and the secretion of several cytokines and growth factors stimulating satellite cell activation [8]. Immediately after an injury to skeletal muscle, the gap formed between the ruptured muscle fibres is filled with a haematoma, where macrophages and fibroblasts are activated, producing additional chemotactic signals (e.g. growth factors, cytokines and chemokines) for the circulating inflammatory cells [1]. The injured myofibres undergo necrosis by autodigestion mediated by intrinsic proteases [9].

Inflammation is clearly a critical component of muscle physiology, and is an important phase in the regenerative process where the goal of treatment is to limit the size of the haematoma and avoid an excessive inflammatory reaction [8]. Functional impairment is associated with perturbed spatial distribution of inflammatory cells, altered identity of the inflammatory infiltrate (cell type and magnitude of influx) and the temporary sequence of these events [8]. On the first day after injury, inflammatory cells including phagocytes invade the haematoma and begin to remove the blood clot [1]. The necrotic area is invaded by small blood vessels, and mononuclear cells, activated macrophages and T-lymphocytes infiltrate the local tissue. These activated lymphocytes simultaneously secrete several cytokines and growth factors which perform a wide range of functions in the inflammation process [10]. For instance, there is an increase in the blood concentration of polymorphonuclear leukocytes (neutrophils, eosinophils and basophils), particularly neutrophils $[1,11,12]$, and this is followed by monocytosis [13]. The level of erythrocytes remains stable but, depending on the lesion type and extent, can decrease because of imprisonment of erythrocytes in the white thrombus (rich in platelets) and due to haemorrhage [14].

The authors' group recently demonstrated that continuous ultrasound in the acute phase of iatrogenic muscle injury promotes erythrocyte reduction and an increase in the concentrations of segmented neutrophils and eosinophils. These modifications suggest increased haemorrhage and an amplified inflammatory response following acute muscle injury [15]. On the other hand, the LIPUS referred effects are decreased wound size, increased collagen deposition, increased ability to withstand tensile loading [16], stimulation of the production of angiogenic factors [17], and increased concentrations of infiltrated neutrophils and monocytes inside and between the basal laminae [2]. Although use of non-thermal therapeutic ultrasound remains widespread in the clinical treatment of muscular injuries, there is a growing body of literature that questions its effectiveness $[18,19]$. However, LIPUS (frequency $1 \mathrm{MHz}$, intensity $0.5 \mathrm{~W} / \mathrm{cm}^{2}$, duty cycle $20 \%$ ) increased the mechanical properties of the injured muscles [20] and, when applied in the first hours after muscular lesion, altered the transduction of cell signalling through modifications in oxidative stress [21], suggesting that parameters of similar applications affect the haematological dynamics in favour of myoregeneration. The aim of this study was to evaluate the effect of LIPUS on the haematological dynamics of different types of leukocytes and erythrocytes after acute muscle injuries.

\section{Materials and methods}

\section{Subjects}

Animal manipulation was performed in accordance with the animal testing guide, and this study was reviewed and approved by the Research Ethics Committee of the University of Cruz Alta (UNICRUZ/Rio Grande do Sul, Brazil). All animals were maintained on a 12-hour dark/light cycle at 20 to $24{ }^{\circ} \mathrm{C}$ and relative humidity of approximately $50 \%$. Food and water were given ad libitum throughout the experimental protocol. The animals' maturation time was 30 weeks. Eighteen mature male Wistar rats (weight 300 to $400 \mathrm{~g}$ ) were used in this study. The rats were randomised before surgery to the control group (submitted to the injury protocol and the therapeutic procedure with the ultrasound equipment turned off; $n=9$ ) and the LIPUS group (submitted to the injury protocol and ultrasonic therapy; $n=9$ ). The groups were submitted to surgical incision on the lateral aspect of the right hind limb according to the injury protocol.

\section{Injury protocol}

The animals were anaesthetised with a combination of xylazine $(7 \mathrm{mg} / \mathrm{kg})$ and ketamine $(70 \mathrm{mg} / \mathrm{kg})$ administered intraperitoneally. A longitudinal surgical incision was made on the skin of the right hind limb to facilitate subcutaneous tissue rupture and to provide easy access to the middle portion of the biceps femoris muscle. Approximately 50\% of muscle fibres were transversally incised. The skin lesion was subsequently closed by surgical suture. This muscle was chosen due to its easy access in rats, and the adequate distance from bone structures which could indirectly interfere with the therapeutic ultrasound stimulus [15].

\section{Ultrasound treatment}

After surgery, the rats in the LIPUS group were treated with ultrasound, applied directly to the injured area. A commercially available ultrasound gel was used as a coupling agent, and all animals were depilated prior to application of the ultrasound treatment. AVATAR V (Model 9075, Biosistemas Equipamentos Eletrônicos Ltda, Amparo, São Paulo, Brazil) was used, calibrated by the manufacturer before the study, with the radiant force method. Ultrasound was applied 
for 3 minutes at a frequency of $1 \mathrm{MHz}$ and an intensity of $0.4 \mathrm{~W} / \mathrm{cm}^{2}$ using a 3 -cm-diameter head (No. TR3CCE02) with an effective radiating area of $5 \mathrm{~cm}^{2}$. The protocol followed a $20 \%$ duty cycle ( $2 \mathrm{~ms}$ on, $8 \mathrm{~ms}$ off) which elicits a spatial-averaged temporal intensity of $0.08 \mathrm{~W} / \mathrm{cm}^{2}$. Circular movement of the treatment head was employed to avoid wave damage [15,22]. The procedure took place 1,8 and 24 hours following surgery. The control animals were manipulated in the same way but with the ultrasound equipment switched off. All animals in both groups received treatment under anaesthesia.

\section{Sample preparation}

Blood samples were collected through venepuncture of the right retro-orbital plexus using a microhaematocrit capillary tube, previously heparinised, and conditioned in Eppendorf tubes with anticoagulants $[15,23]$. The samples were collected 1,8 and 24 hours following surgery.

A Neubauer chamber and a macrodilution technique were used to determine the number of leukocytes per millilitre of blood: $20 \mu \mathrm{l}$ blood was diluted in $4 \mathrm{ml}$ Türk liquid and the number of leukocytes in the four wide-angle squares was counted. This number was multiplied by 50 and the results were given in microlitres. Before the cell count, the Neubauer chamber was placed inside an inverted Petri dish containing a moist cotton ball for 5 minutes to allow cell sedimentation. To observe the morphology and perform the differential leukocyte count, to which the examiners were blinded, a blood smear on a slide was stained with Romanowsky stain. After being washed and dried at room temperature, the slide was examined under an optical microscope. One hundred cells were counted according to the Shilling zigzag technique, and the values were expressed in $\times 10^{3} / \mathrm{mm}^{3}$.

A Neubauer chamber and a macrodilution technique were also used to determine the number of erythrocytes per millilitre of blood. Marcano liquid was used as the diluent for the erythrocyte count. Four millilitres of diluent was mixed with $20 \mu \mathrm{l}$ blood, and the erythrocytes in the five middle squares of the central square were counted. This number was multiplied by 10000 and the values were expressed in $\times 10^{5} / \mathrm{mm}^{3}$. In the haematocrit determination, the microhaematocrit tube was filled approximately three-quarters full with blood and one of its ends was sealed using a Bunsen burner. The capillary tube was placed in a microcentrifuge for 5 minutes at 3000 revolutions/minute, and the reading was carried out on the appropriate card. For quantification of the haematological variables, two Neubauer chambers were counted and the average was calculated. When a difference of more than $10 \%$ was found between the two results, a recount was performed.

\section{Statistical analysis}

All values are presented as means (standard errors), and variations between groups are presented as mean differences and $95 \%$ confidence intervals $(\mathrm{CI})$ for those differences. A haematological comparison within each group at the three time periods (1, 8 and 24 hours post-surgery) and between the groups (control vs LIPUS) was made by comparing the curves for the different times using a two-way analysis of variance with repeated measures for the two factors (group and time), followed by the Bonferroni post-hoc test. A probability of less than $5 \%$ was considered to be statistically significant.

\section{Results}

Data variations in each group at the three times and between the two groups are shown in Table 1.

\section{Time variation}

A progressive reduction in the haematocrit was seen following surgery $(P<0.001)$ for both groups. The erythrocyte and segmented neutrophil counts were reduced at 1 hour postsurgery compared with 8 and 24 hours $(P<0.001)$ for both groups. In the control group, the lymphocyte count increased at 1 and 24 hours post-surgery $(P<0.001)$; however, in the LIPUS group, this increase was only observed at 24 hours post-surgery $(P<0.001)$. The monocyte count only increased at 24 hours post-surgery in the control group $(P<0.017)$, and the eosinophil concentration increased at 24 hours postsurgery in the LIPUS group $(P<0.014)$. However, the total number of leukocytes, young neutrophils and polibocytes did not change with time throughout this study.

\section{Variation between groups}

The LIPUS group showed a decrease in the total leukocyte count $(P<0.001)$ compared with the control group at 1,8 and 24 hours post-surgery (Fig. 1A), with $33 \%$ reduction at 1 hour $(P<0.01$, mean difference $-2781,95 \%$ CI -4508 to -1054$), 34 \%$ reduction at 8 hours $(P<0.01$, mean difference $-2698,95 \% \mathrm{CI}-4425$ to -971$)$ and $36 \%$ reduction at 24 hours $(P<0.05$, mean difference $-1862,95 \%$ CI -3642 to -81$)$. The segmented neutrophils showed a reduction of approximately $39 \%$ in the LIPUS group $(P<0.006$, mean difference $-1478,95 \% \mathrm{CI}-2637$ to -509$)$ at 1 hour post-surgery (Fig. 1B).

After surgery, the blood concentration of monocytes increased in the control group alone. At 8 hours post-surgery $(P<0.05$, mean difference $-440,95 \% \mathrm{CI}-770$ to -109$)$, the difference was nearly two times greater than that found in the LIPUS group (Fig. 1C), with no difference seen at 24 hours post-surgery. The blood concentration of lymphocytes increased for both groups, but to differing extents $(P<0.001)$. The values were approximately $46 \%$ lower at 8 hours post-surgery for the LIPUS group $(P<0.05$, mean difference $-2176,95 \% \mathrm{CI}-3710$ to -641 ), demonstrating a delay in the lymphocyte response to the muscular lesion (Fig. 1D). Differences were not observed in the haematocrit or concentrations of erythrocytes, neutrophil rods, polibo- 
Table 1

Haematological variables after muscle lesion and application of low-intensity pulsed ultrasound (LIPUS) in a controlled laboratory study.

\begin{tabular}{|c|c|c|c|c|c|c|c|}
\hline \multirow[t]{2}{*}{ Haematological variable } & \multirow[t]{2}{*}{ Unit } & \multirow[t]{2}{*}{ Group } & \multicolumn{3}{|l|}{ Collections } & \multicolumn{2}{|c|}{ ANOVA $P$ value } \\
\hline & & & 1 hour & 8 hours & 24 hours & Group & Time \\
\hline \multirow[t]{2}{*}{ Leukocytes } & \multirow[t]{2}{*}{$\times 10^{3} / \mathrm{mm}^{3}$} & Control & $9017.2(481)$ & $8078.2(501)$ & $8192.3(646)$ & \multirow[t]{2}{*}{$<0.001$} & \multirow[t]{2}{*}{0.589} \\
\hline & & LIPUS & $6189.8(450)^{\mathrm{a}}$ & $5371.3(378)^{\mathrm{a}}$ & $6059.1(503)^{\mathrm{a}}$ & & \\
\hline \multirow[t]{2}{*}{ Segmented neutrophils } & \multirow[t]{2}{*}{$\times 10^{3} / \mathrm{mm}^{3}$} & Control & $5033.1(397)$ & $2426.6(236)^{b}$ & $2498.5(239)^{\mathrm{b}}$ & \multirow[t]{2}{*}{0.006} & \multirow[t]{2}{*}{$<0.001$} \\
\hline & & LIPUS & $3594.8(191)^{\mathrm{a}}$ & $2240.0(261)^{b}$ & $1967.2(210)^{\mathrm{b}}$ & & \\
\hline \multirow[t]{2}{*}{ Young neutrophils (rods) } & \multirow[t]{2}{*}{$\times 10^{3} / \mathrm{mm}^{3}$} & Control & $20.4(13)$ & $23.5(14)$ & $67.6(30)$ & \multirow[t]{2}{*}{0.088} & \multirow[t]{2}{*}{0.344} \\
\hline & & LIPUS & $78.7(28)$ & $52.5(35)$ & $84.2(23)$ & & \\
\hline \multirow[t]{2}{*}{ Polibocytes } & \multirow[t]{2}{*}{$\times 10^{3} / \mathrm{mm}^{3}$} & Control & $248.3(155)$ & $161.6(74)$ & $29.8(13)$ & \multirow[t]{2}{*}{0.216} & \multirow[t]{2}{*}{0.075} \\
\hline & & LIPUS & $156.2(61)$ & $37.6(21)$ & $12.7(8)$ & & \\
\hline \multirow[t]{2}{*}{ Monocytes } & \multirow[t]{2}{*}{$\times 10^{3} / \mathrm{mm}^{3}$} & Control & $505.0(98)$ & $815.5(126)$ & $875.3(124)^{\mathrm{b}}$ & \multirow[t]{2}{*}{$<0.001$} & \multirow[t]{2}{*}{0.017} \\
\hline & & LIPUS & $362.0(71)$ & $375.4(70)^{\mathrm{a}}$ & $564.7(58)$ & & \\
\hline \multirow[t]{2}{*}{ Eosinophils } & \multirow[t]{2}{*}{$\times 10^{3} / \mathrm{mm}^{3}$} & Control & $88.9(25)$ & $161.0(43)$ & $149.2(16)$ & \multirow[t]{2}{*}{0.328} & \multirow[t]{2}{*}{0.014} \\
\hline & & LIPUS & $46.8(14)$ & $121.2(31)$ & $151.4(22)^{b}$ & & \\
\hline \multirow[t]{2}{*}{ Lymphocytes } & \multirow[t]{2}{*}{$\times 10^{3} / \mathrm{mm}^{3}$} & Control & $3120.7(268)$ & $4759.7(459)^{\mathrm{b}}$ & $4346.2(350)^{\mathrm{b}}$ & \multirow[t]{2}{*}{0.003} & \multirow[t]{2}{*}{$<0.001$} \\
\hline & & LIPUS & $1529.6(433)$ & $2584.1(356)^{\mathrm{a}}$ & $3256.5(255)^{\mathrm{b}}$ & & \\
\hline \multirow[t]{2}{*}{ Haematocrit } & \multirow[t]{2}{*}{$\%$} & Control & $49.1(1.3)$ & $43.5(1.6)^{b}$ & $37.5(1.1)^{\mathrm{b}, \mathrm{c}}$ & 0.925 & $<0.001$ \\
\hline & & LIPUS & $49.2(0.9)$ & $43.6(0.1)^{\mathrm{b}}$ & $37.5(1.1)^{\mathrm{b}, \mathrm{c}}$ & & \\
\hline Erythrocytes & $\times 10^{5} / \mathrm{mm}^{3}$ & Control & $10.1(0.3)$ & $7.3(0.1)^{\mathrm{b}}$ & $7.1(0.2)^{b}$ & 0.184 & $<0.001$ \\
\hline & & LIPUS & $10.8(0.3)$ & $7.4(0.2)^{\mathrm{b}}$ & $7.3(0.3)^{b}$ & & \\
\hline
\end{tabular}

Mean \pm standard error.

$P$, evaluation of the comparisons between groups using two-way analysis of variance (ANOVA) with repeated measures followed by the Bonferroni post-hoc test.

a $P<0.05$ variation between the groups.

b $P<0.05$ variation over time vs 1 hour post-surgery.

c $P<0.05$ variation over time vs 8 hours post-surgery.

cytes and eosinophils between the groups throughout the experiment.

\section{Discussion}

LIPUS reduced the total leukocyte count on the first day after iatrogenic muscular lesion, ascribed to a reduction in the segmented neutrophil count at 1 hour post-surgery and to a delay in the increase in monocytes and lymphocytes at 8 hours post-surgery.

Since neutrophils are the most abundant white blood cells, a significant number are collected passively by the provisory thrombus during the disruption of vessels [11,24]. These subsequently migrate to the surface of the lesion to form a barrier against the invasion of micro-organisms, and to promote the active recruitment of more neutrophils from adjacent non-injured vessels, promoting neutrophilia in the blood $[11,22,25]$. The satellite cells and necrotised parts of the myofibres release various substances (wound hormones) that serve as chemoattractants, enhancing extravasation of the inflammatory cells [1]. For instance, 1 day after a lesion, neutrophils will represent $50 \%$ of the cells that migrated to the site [25]. This may explain the systemic reduction of these cells in both groups in the present study. Although neutrophil infiltration has been suggested as a contributor, there is no clear evidence to support this claim [13].

LIPUS stimulated a major reduction in the number of segmented neutrophils at 1 hour post-surgery, suggesting that this therapeutic intervention promoted a greater displacement of these cells to the lesion site due to the reduction of these cells in the blood. This phenomenon can be partly explained by the upregulation of prostaglandin $E_{2}$ and leukotriene $\mathrm{B}_{4}$ (arachidonic acid metabolite), showing that ultrasound (3.0 MHz) treatment can stimulate an inflammatory response rather than an anti-inflammatory effect in the acute phase of ligament injury. The prolonged, early and late onset of ultrasound treatment has been shown to have similar effects on the upregulation of prostroglandin $\mathrm{E}_{2}$ and leukotriene $\mathrm{B}_{4}$ [26]. However, the concentration of young neutrophils did not differ between the groups at 1,8 or 24 hours post-surgery, suggesting that LIPUS does not alter the formation of new neutrophils in the first 24 hours after injury. These data suggest that LIPUS may promote a contrary effect, with greater attraction of mature neutrophils to the lesion site, as described in the literature [2], but without stimulation of the formation of new neutrophils, favouring muscular regeneration after this period.

Neutrophils are replaced by monocytes [1], and these are abundant at the lesion site between the second and the fifth day after injury, promoting a progressive increase of these cells in the blood [13]. The study results suggest that the progressive increase of these cells in the blood occurred mainly in the control group by 24 hours; the LIPUS group demonstrated a delay in the monocyte response, with a lower concentration at 8 hours, and their blood concentration did not change during the experiment. Monocytes are transformed into macrophages that actively engage in proteolysis and phagocytosis of the necrotic material by the release of lysosomal enzymes [27]. This process preserves cylinders of the 
Leukocytes

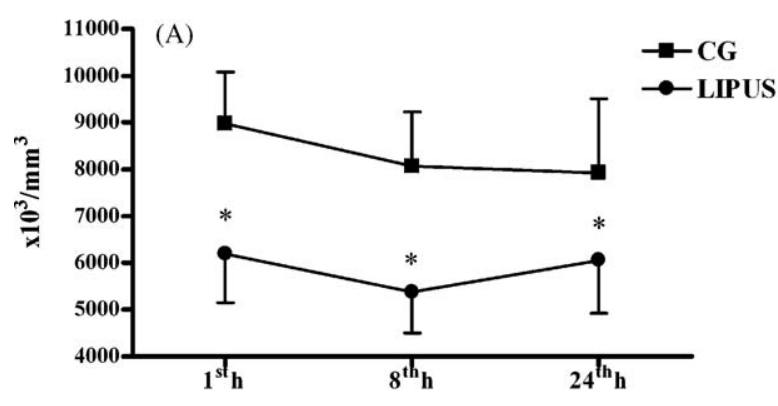

Monocytes

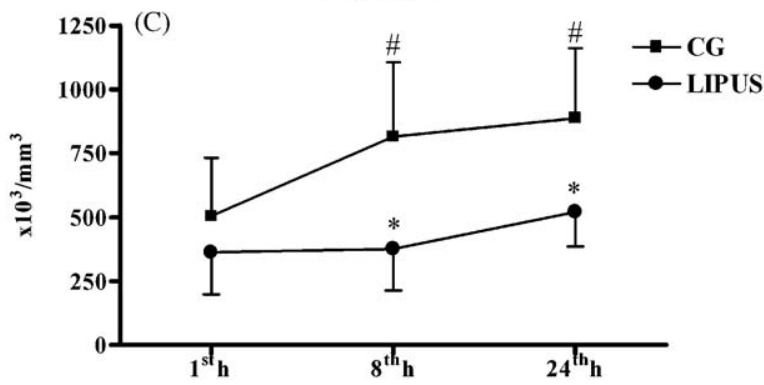

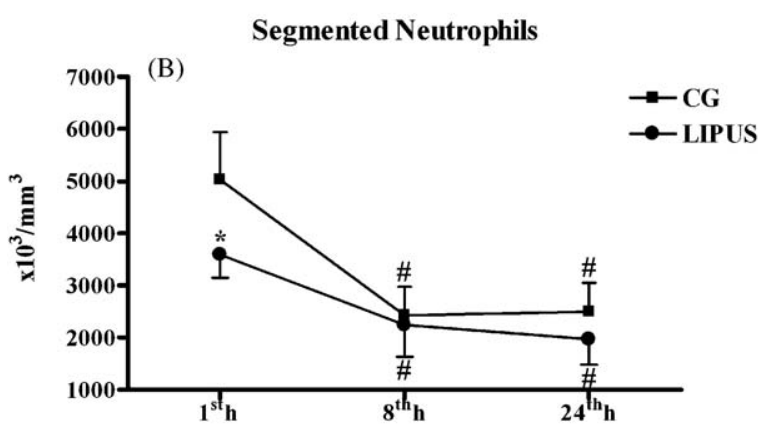

Lymphocytes

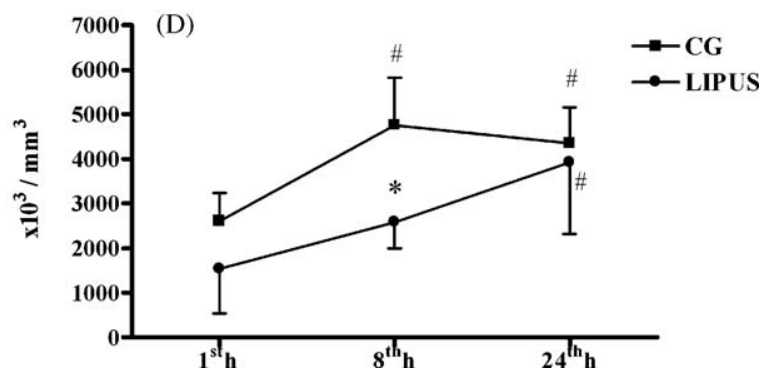

Fig. 1. Haematological concentrations of the different types of leukocytes during the experiment. Values are presented as means and standard errors $\left(\times 10^{3} / \mathrm{mm}^{3}\right)$. LIPUS, low-intensity pulsed ultrasound; CG, control group. Groups were compared using two-way analysis of variance followed by the Bonferroni post-hoc test. $* P<0.05$ variation between the groups; ${ }^{\#} P<0.05$ variation over time vs 1 hour post-surgery; ${ }^{\dagger} P<0.05$ variation over time vs 8 hours post lesion.

basal lamina and the injured myofibres and, consequently, serves as a scaffold in which the viable satellite cells begin the formation of new myofibres [1]. However, a decrease in this selectivity can exacerbate secondary damage [13]. LIPUS favours the migration of monocytes to the lesion site [2], thus reducing their concentration in the blood at this time; however, as time passes, the lower concentration of these cells may also favour muscular regeneration.

The monocytes also present their peptides due to their greater complex of histocompatibility with $\mathrm{T}$ auxiliary cells a link between the innate immune system and the adaptative one [13]. The present study found that the muscular lesion promoted a progressive increase in the lymphocyte count in both groups, and LIPUS weakened this increase at 8 hours post-surgery and delayed this response compared with the first hour post-surgery. Lymphocytes are attracted to the lesion site in the same quantity as monocytes and, from 14 days onwards, leukocytes predominate at the lesion site [25]. In the present study, both lymphocytes and leukocytes presented a delay to this systemic response, suggesting that LIPUS has an anti-inflammatory effect.

Eosinophils arrive at the lesion site in the last reparation phases [28]. The results suggest that, at 24 hours post-surgery, the concentration of these cells increases in comparison with 1 hour post-surgery; no differences were found between the groups.

Both erythrocyte counts is reduced compared with 1 hour post-surgery. The reduction in erythrocyte concentration in the blood is due to endothelium injury which leads to a sequence of events, beginning with platelet deposition which causes the formation of a white thrombus (rich in platelets) that provisorily tamponades the endothelial lesion [14]. This thrombus is quickly infiltrated by fibrin and the erythrocytes are captured, forming a red thrombus; this is the main cause of occlusion of the disrupted blood vessel [29]. However, the repeated blood collections in this study may have influenced the concentration of erythrocytes, being a limitation inherent to the study protocol.

The haematological reduction in total leukocyte count at 1,8 and 24 hours post-surgery may be explained by the displacement of these cells to the lesion site and/or their reduced formation in the haematohepatic system. Through the action of eicosanoids, cytokines produced by microphages, mastocytes, stromal cells and other mediators, the endothelial cells of the non-lesioned vessels are induced to express the adhesion molecules for leukocytes in their membranes [30]. LIPUS could interfere with these mediators and hence reduce the transduction of cell signalling and exert a role in modulation of the inflammatory response. The possible antiinflammatory mechanisms of LIPUS may be the antioxidant effect [21], increase in the differentiation of muscular lineage cells [31], increase in satellite cell number [2], associated mechanisms fibroblast growth factor and insulin-like growth factor-I in the presence of transforming growth factor-beta, which inhibits differentiation and stimulates cell proliferation [32], resulting in improvement of the mechanical properties (rigidity, strengthening and maximum load limit) of the lesioned muscle [20]. Ultrasonication, or 'micromassage', of the tissue produces a change in membrane permeability and stimulates the transport of second messenger substances (e.g. 
calcium across the cell membrane), leading to the proliferation of myogenic cells and satellite cells $[33,34]$.

\section{Study limitations}

The reasons for these different findings are not readily apparent, perhaps because the mechanisms through which ultrasound affects tissue repair are obscure. A combination of factors, including the type of tissue examined, model of injury and mode/intensity/frequency of ultrasound treatment, may account for the different findings [32]. Future studies should include histological analysis and tissue histochemistry to make it feasible to study the relationship between the haematological data and tissue effects. However, caution should be taken in extrapolating these results to human clinical treatments, as the findings are limited by the variables studied, the treatment protocols and the specific injury. Finally, the area treated by LIPUS must be considered in relation to the corporal total body area of the animal.

\section{Conclusion}

This study showed that LIPUS application in the acute phase of an iatrogenic muscular lesion in rats promotes alterations in haematological dynamics. These modifications are characterised by a reduction in the total leukocyte count due to the lower concentration of segmented neutrophils at 1 hour post-surgery, and a delay in the increase of monocytes and lymphocytes observed at 8 hours post-surgery, without altering the level of circulating erythrocytes. These data suggest that LIPUS has an anti-inflammatory effect. However, further studies are needed to gain a better understanding of this interaction and its therapeutic application in patients with muscular lesions.

Ethical approval: Animal manipulation was performed in accordance with the animal testing guide (in agreement with the Brazilian Legislation no. 11.794/2008 for Procedures for the Scientific Use of Animals), and this study was reviewed and approved by the Research Ethics Committee of the University of Cruz Alta (UNICRUZ/Rio Grande do Sul), Protocol Number 002/2008.

Funding: Research support programme of the University of Cruz Alta.

Conflict of interest: None declared.

\section{References}

[1] Jarvinen TA, Jarvinen TL, Kaariainen M, Kalimo H, Jarvinen M. Muscle injuries: biology and treatment. Am J Sports Med 2005;33:745-64.

[2] Rantanen J, Thorsson O, Wollmer P, Hurme T, Kalimo H. Effects of therapeutic ultrasound on the regeneration of skeletal muscle myofibers after experimental muscle injury. Am J Sports Med 1999;27:54-9.
[3] Karnes JL, Burton HW. Continuous therapeutic ultrasound accelerates repair of contraction-induced skeletal muscle damage in rats. Arch Phys Med Rehabil 2002;83:1-4.

[4] Wilkin LD, Merrick MA, Kirby TE, Devor ST. Influence of therapeutic ultrasound on skeletal muscle regeneration following blunt contusion. Int J Sports Med 2004;25:73-7.

[5] Suzuki A, Takayama T, Suzuki N, Sato M, Fukuda T, Ito K. Daily lowintensity pulsed ultrasound-mediated osteogenic differentiation in rat osteoblasts. Acta Biochim Biophys Sin 2009;41:108-15.

[6] Gan BS, Huys S, Sherebrin MH, Scilley CG. The effects of ultrasound treatment on flexor tendon healing in the chicken limb. J Hand Surg 1995;20:809-14.

[7] Takakura Y, Matsui N, Yoshiya S, Fujioka H, Muratsu H, Tsunoda $\mathrm{M}$, et al. Low-intensity pulsed ultrasound enhances early healing of medial collateral ligament injuries in rats. J Ultrasound Med 2002;21: 283-8.

[8] Worrell TW. Factors associated with hamstring injuries. An approach to treatment and preventative measures. Sports Med 1994;17:338-45.

[9] Lille ST, Lefler SR, Mowlavi A, Suchy H, Boyle EM, Farr Jr AL, et al. Inhibition of the initial wave of NF-kappaB activity in rat muscle reduces ischemia/reperfusion injury. Muscle Nerve 2001;24:534-41.

[10] Douglas MR, Morrison KE, Salmon M, Buckley CD. Why does inflammation persist: a dominant role for the stromal microenvironment? Expert Rev Mol Med 2002;4:1-18.

[11] St Pierre Schneider B, Correia LA, Cannon JG. Sex differences in leukocyte invasion in injured murine skeletal muscle. Res Nurs Health 1999;22:243-50.

[12] Northoff H, Berg A, Weinstock C. Similarities and differences of the immune response to exercise and trauma: the IFN-concept. Can J Physiol Pharmacol 1998;76:497-504.

[13] Smith C, Kruger MJ, Smith RM, Myburgh KH. The inflammatory response to skeletal muscle injury: illuminating complexities. Sports Med 2008;38:947-69.

[14] Lefkovits J, Plow EF, Topol EJ. Platelet glycoprotein IIb/IIIa receptors in cardiovascular medicine. N Engl J Med 1995;332:1553-9.

[15] Plentz RDM, Stoffel PB, Kolling GJ, Costa ST, Beck C, Signori LU. Hematological changes produced by $1 \mathrm{MHz}$ continuous ultrasound, applied during the acute phase of iatrogenic muscle injury in rats. Rev Bras Fisioter 2008;12:495-501.

[16] Byl N, McKenzie AL, Wong T, West JM, Hunt TK. Incisional wound healing: a controlled study of low and high dose ultrasound. J Orthop Sports Phys Ther 1993;18:619-28.

[17] Reher P, Doan N, Bradnock B, Meghji S, Harris M. Effect of ultrasound on the production of IL-8, basic FGF and VEGF. Cytokine 1999;11:416-23.

[18] Almekinders LC. Anti-inflammatory treatment of muscular injuries in sport. An update of recent studies. Sports Med 1999;28:383-8.

[19] Baker KG, Robertson VJ, Duck FA. A review of therapeutic ultrasound: biophysical effects. Phys Ther 2001;81:1351-8.

[20] Matheus JPC, Oliveira FB, Gomide LB, Milani JGPO, Volpon JB, Shimano AC. Effects of therapeutic ultrasound on the mechanical properties of skeletal muscles after contusion. Rev Bras Fisioter 2008;12:241-7.

[21] Freitas LS, Freitas TP, Silveira PC, Rocha LG, Pinho RA, Streck EL. Effect of therapeutic pulsed ultrasound on parameters of oxidative stress in skeletal muscle after injury. Cell Biol Int 2007;31:482-8.

[22] Chang CJ, Hsu SH, Lin FT, Chang H, Chang CS. Lowintensity-ultrasound-accelerated nerve regeneration using cell-seeded poly(D,L-lactic acid-co-glycolic acid) conduits: an in vivo and in vitro study. J Biomed Mater Res B Appl Biomater 2005;75:99-107.

[23] Chen J, Yang WL, Li G, Qian J, Xue JL, Fu SK, et al. Transfection of mEpo gene to intestinal epithelium in vivo mediated by oral delivery of chitosan-DNA nanoparticles. World J Gastroenterol 2004;10:1126.

[24] Foxman EF, Campbell JJ, Butccher E. Multistep navigation and combinatorial control of leukocyte chemotaxis. J Cell Biol 1997;139:1349-60. 
[25] Engelhard E, Toksoy A, Goobeler M, Debus S, Brücker EB, Gillitzer R Chemokines IL-8, Groa, MCP-1, IP-10, and Mig are sequentially and differentially expressed during phasespecific infiltration of leucocyte subsets in human wound healing. Am J Pathol 1998;153:1849-60.

[26] Leung MC, Ng GY, Yip KK. Effect of ultrasound on acute inflammation of transected medial collateral ligaments. Arch Phys Med Rehabil 2004;85:963-6.

[27] Farges MC, Balcerzak D, Fisher BD, Attaix D, Béchet D, Ferrara $\mathrm{C}$, et al. Increased muscle proteolysis after local trauma mainly reflects macrophage-associated lysosomal proteolysis. Am J Physiol Endocrinol Metab 2002;282:326-35.

[28] Wong DT, Donoff RB, Yang J, Song BZ, Matossian K, Nagura N, et al. Sequential expression of transforming growth factors alpha and beta 1 by eosinophils during cutaneous wound healing in the hamster. Am J Pathol 1993;143:130-42.
[29] Davies MJ. A macro and micro view of coronary vascular insult in ischemic heart disease. Circulation 1990;82:II38-46.

[30] Gerszten RE, Garcia-Zepeda EA, Lim YC, Yoshida M, Ding HA, Gimbrone MA, et al. MCP-1 and IL-8 trigger firm adhesion of monocytes to vascular endothelium under flow conditions. Nature 1999;398:718-23.

[31] Piedade MCB, Galhardo MS, Battlehner CN, Ferreira MA, Caldini EG, Toledo OMS. Effect of ultrasound therapy on the repair of gastrocnemius muscle injury in rats. Ultrasonics 2008;48:403-11.

[32] Huard J, Li Y, Fu FH. Muscle injuries and repair: current trends in research. J Bone Joint Surg Am 2002;84:822-32.

[33] Dinno MA, Dyson M, Young SR, Mortimer AJ, Hart J, Crum L. The significance of membrane changes in the safe and effective use of therapeutic and diagnostic ultrasound. Phys Med Biol 1989;34:1543-52.

[34] Mortimer AJ, Dyson M. The effect of therapeutic ultrasound on calcium uptake in fibroblasts. Ultrasound Med Biol 1988;14:499-506.

Available online at www.sciencedirect.com

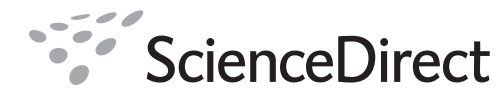

